\title{
Non-invasive stool antigen test for screening of Helicobacter pylori infection and assessing efficacy of treatment in patients with peptic ulcer
}

\author{
Dr Rezina Karim ${ }^{\prime}$, SM Moslehuddin Ahmed', Fahmida Begum \\ ${ }^{1}$ Assistant Professor ${ }^{3}$ Associate Professor, Department of Microbiology; ${ }^{2}$ Head and Professor, Department of Community Medicine; \\ Uttara Adhunik Medical College, Dhaka, Bangladesh.
}

\section{Abstract}

Helicobacter pylori infection is one of the most common infections in humans, with an estimated $50 \%$ of the world population being infected. The infection is strongly associated with chronic gastritis, peptic ulcer, adenocarcinoma and non-Hodgkin's lymphoma of stomach. The prevalence of infection is high in developing countries, demanding a reliable diagnostic and treatment method. The present study was designed to investigate the monoclonal antibody-based $H$. Pylori stool antigen test to screen $H$. pylori infection and assess efficacy of treatment in patients with peptic ulcer. A total of 89 patients who underwent upper gastrointestinal endoscopy from July 2007 to June 2008 at Bangabandhu Sheikh Mujib Medical University Hospital, Dhaka, Bangladesh were included in the study. Endoscopic findings showed that out of 89 patients, 54 (60.7\%) had duodenal ulcers, $24(27 \%)$ had antral erosion and $5(5.6 \%)$ had gastric ulcers. With RUT (rapid urease test) and histopathology of biopsy samples of 89 patients, $78(87.6 \%)$ patients were found to be $H$. pylori positive. Stool antigen test was positive in $72(92.3 \%)$ out of $78 \mathrm{H}$. pylori positive patients. The monoclonal stool antigen test (SAT) revealed $92.3 \%$ sensitivity and specificity of $100 \%$ before treatment. Among 52 follow-up patients (after treatment), 5 (9.6\%) patients were detected positive by histology, RUT and stool antigen test, and $35(67.3 \%)$ patients were negative by 3 tests. So the monoclonal SAT revealed $100 \%$ sensitivity and $100 \%$ specificity after treatment. The monoclonal stool antigen test is highly sensitive and a specific tool for diagnosis of $H$. pylori infection before therapy and can assess the success of eradication after therapy. It also offers the advantage of specificity and reliability over the invasive test. It is easy and quick to use, non-invasive and does not require any special technology.

Keywords: Helicobacter pylori, peptic ulcer, monoclonal SAT, non-invasive, Bangladesh.

\section{Introduction}

Helicobacter pylori (H. pylori), a gram-negative bacterium, was first isolated from humans in 1982. ${ }^{1}$ H. pylori infection is one of the most common infections in humans, with estimated $50 \%$ of the world population being infected. ${ }^{2}$ The infection is strongly associated with chronic gastritis, peptic ulcer, adenocarcinoma and non-Hodgkin's lymphoma of stomach. ${ }^{3}$ An infected individual has an estimated lifetime risk of 10$20 \%$ for the development of peptic ulcer disease, which is at least 3-4 folds higher than in non-infected subjects, and $<1 \%$ will develop gastric cancer. ${ }^{2} H$. pylori infection can be diagnosed in $90-100 \%$ of duodenal ulcer patients and in 60 $100 \%$ of gastric ulcer patients. ${ }^{4}$ A recent study found that the prevalence of $H$. pylori infection was higher in Bangladeshi than in Japanese subjects ( 60.2 and $45.1 \%$, respectively) with abdominal complaints who underwent endoscopy examinations and had no history of $H$. pylori eradication. ${ }^{5} \mathrm{H}$. Pylori infection is primarily acquired during childhood and typically clusters within families. A community-based crosssectional study in asymptomatic young Bangladeshi children

\section{Practice points}

- H. pylori infection is one of the most common infections in humans, with an estimated $50 \%$ of the world population being infected.

- The prevalence of infection is high in developing countries, demanding a reliable diagnosis and treatment method.

- The monoclonal stool antigen test is easy and quick to use, non-invasive and does not require any special technology.

- In the present study, the monoclonal SAT revealed $92.3 \%$ sensitivity and specificity of $100 \%$ before treatment, and $100 \%$ sensitivity and $100 \%$ specificity after treatment.

- Based on this performance, the monoclonal SAT can be used for screening $H$. pylori infection and assessing efficacy of treatment in the healthcare settings of Bangladesh.

Correspondence: Dr. Rezina Karim, Assistant Professor, Department of Microbiology, Uttara Adhunik Medical College, Dhaka-1230, Bangladesh.E-mail: karimrezina@yahoo.com. 
(2-5 years) was done in rural and peri-urban areas by Urea Breath Tests (UBT) and found a $72 \%$ H. Pylori infection rate. ${ }^{6}$ In Pakistan, the infection rate with $H$. Pylori was about $83 \%$ in adult patients undergoing upper GI endoscopy for various reasons. ${ }^{7}$ The prevalence of $H$. Pylori infection varies with age, socioeconomic condition, education level. ${ }^{8}$ The period of acquisition of infection is in childhood and the likelihood increases with age. ${ }^{9}$ Between the ages of 40-60 years a prevalence rate of $30-40 \%$ was found in USA and Australia. ${ }^{10}$ In the developing world, $80 \%$ of the populations are infected in adulthood. ${ }^{11}$ Transmission occurs from person to person through fecal-oral, oral-oral and gastrooral routes. The connection of H. Pylori with several clinical conditions has increased the demands for treatment of infection and thereby has increased the interest for reliable diagnostic method.

During the past decade several methods, both direct and indirect have been developed for diagnosing. Non-invasive tests are useful for primary diagnosis and are also useful in patients who cannot tolerate endoscopy. ${ }^{12}$ Direct methods (invasive) involve endoscopy and examination of gastric biopsies from antrum and corpus, for culture, rapid urease test, histopathology. Noninvasive methods, include urea breath test, serology and stool antigen test. The urea breath test has a high degree of accuracy whether $\left[{ }^{14} \mathrm{C}\right]$ - based or $\left[{ }^{13} \mathrm{C}\right]$-based, and is in may studies considered to be the reference standard ${ }^{13-15}$ However concerns over radiation may limit the use of $\left[{ }^{14} \mathrm{C}\right]$-urea and the employment of the $\left[{ }^{13} \mathrm{C}\right]-$ urea breath test requires expensive equipment for analysis. ${ }^{16}$

In recent years a new diagnostic tool, the stool antigen test, has been available and the main advantages are the noninvasive nature of this procedure and patients can obtain a stool sample at home for laboratory analysis. It is very rapid and easy test and can be used in a situation where the culture facilities are not available. Result can be given to a patient within 2 hours after stool collection so that prompt therapy can be introduced. The first commercially available stool test was based on polyclonal antibodies and has been thoroughly evaluated with reports of a sensitivity in the range of 86$100 \%{ }^{17}$ and a specificity of $70-100 \% .{ }^{18}$ A second generation of kits, based on monoclonal antibodies, has already been used for several years. Though the results on monoclonal stool antigen test (SAT) were not satisfactory in study conducted by Quesada et al. $\dot{ }^{19}$ however, Kolho et al. ${ }^{20}$ Hooton et al., ${ }^{21}$ and Frenck et al.,22 demonstrated good results with monoclonal SAT. The present study was designed to investigate the monoclonal antibody-based $H$. Pylori stool antigen test to screen $H$. pylori infection and assess efficacy of treatment in patients with peptic ulcer at Bangabandhu Sheikh Mujib Medical University Hospital, Dhaka, Bangladesh.

\section{Materials and methods}

A cross-sectional study was conducted among adult patients with peptic ulcers in Bangabandhu Sheikh Mujib Medical University (BSMMU) Hospital, Dhaka, Bangladesh from
July 2007 to June 2008. A structured questionnaire was used to collect the socio-demographic information of the patients. Patients were diagnosed by clinical history and subsequent endoscopic findings and a total of 89 peptic ulcer patients were recruited for the study. Three biopsy samples were taken from the patients for RUT (rapid urease test) and histopathology to assess the $H$. pylori status of the patients. Among 89 patients, 78 (87.6\%) patients were found to be $H$. pylori positive, who then received $H$. pylori eradication therapy. All the $H$. positive subjects received the same eradication therapy. Out of 78 patients, 52 patients attended the clinic for further follow-up. The follow-up patients were then assessed for $H$. pylori again using similar procedure (biopsy samples for RUT and histopathology). Stools collected from $78 \mathrm{H}$. pylori positive and 52 follow-up patients and were stored $-20^{\circ} \mathrm{C}$ until tested by the monoclonal SAT. The research protocol was also approved by the ethics committee of the BSMMU. Written informed consent forms were signed by each participant.

\section{Sample collection and transportation}

Endoscopic examination of the upper GIT of the patients was done by the endoscopist. Three biopsy tissues were obtained from the gastric antrum and one from upper corpus from each patient. Two biopsy specimens of the antrum and one of the corpus was fixed in 10\% buffered formalin for histopathology. The one remaining biopsy specimen was kept immediately for RUT. Stool samples were collected in an airtight transport container from all patients for stool antigen test.

\section{Monoclonal SATfor H. pylori}

Monoclonal SAT (Premier, Platinum HpSA PLUS, Meridian Bioscience, Italy), a commercially available enzyme immunoassay kit, was used to detect $H$. pylori antigens present in human stool. It utilizes a plurality of monoclonal and $H$. pylori capture antibodies adsorbed to microwells.

\section{Statistical analysis}

All statistical analyses were performed using the Statistical Package for the Social Sciences, version 16.0 (SPSS, Inc, Chicago, IL). Descriptive data are given as frequencies and percentages. Differences in distributions were analyzed by chi square test. The level of significance was set at $P<0.05$.

\section{Results}

Table 1 outlines the details of the socio-demographic variables and $H$. pylori status of the study population. Endoscopic findings showed that out of 89 study population, $54(60.7 \%)$ had duodenal ulcer, $24(27 \%)$ had antral erosion and $5(5.6 \%)$ had gastric ulcer (Table 2). With RUT and histopathology of biopsy samples of 89 patients, 78 (87.6\%) patients were found $H$. pylori positive. Table 3 shows stool antigen test results and the $H$. pylori status of the patients before treatment. The stool antigen test was positive in $72(92.3 \%)$ out of $78 \mathrm{H}$. pylori positive patients. 
Table 1: ANC registration and facilitator

\begin{tabular}{|c|c|c|c|c|}
\hline \multirow[t]{2}{*}{ Variables } & \multirow[t]{2}{*}{ No of respondents } & \multicolumn{3}{|c|}{ H. pylori status } \\
\hline & & Positive (\%) & Negative $(\%)$ & Indeterminate (\%) \\
\hline Age & & & & \\
\hline$<20$ years & 1 & $1(100 \%)$ & $0(0 \%)$ & $0(0 \%)$ \\
\hline $21-40$ years & 59 & $51(86.4 \%)$ & $7(11.9 \%)$ & $1(1.7 \%)$ \\
\hline 41-60 years & 29 & $26(89.7 \%)$ & $1(3.4 \%)$ & $2(6.9 \%)$ \\
\hline Gender & & & & \\
\hline Male & 66 & $55(83.3 \%)$ & $8(12.1 \%)$ & $3(4.5 \%)$ \\
\hline Female & 23 & $23(100 \%)$ & $0(0 \%)$ & $0(0 \%)$ \\
\hline Marital status & & & & \\
\hline Married & 76 & $67(88.2 \%)$ & $6(7.9 \%)$ & $3(3.9 \%)$ \\
\hline Unmarried & 13 & $11(84.6 \%)$ & $2(15.4 \%)$ & $0(0 \%)$ \\
\hline Socio-economic status & & & & \\
\hline Lower $(<5000 /)$ & 39 & $34(87.2 \%)$ & $3(7.7 \%)$ & $2(5.1 \%)$ \\
\hline Middle (5001/-15000/) & 37 & $33(89.2 \%)$ & $3(8.1 \%)$ & $1(2.7 \%)$ \\
\hline Upper $(>15000 /)$ & 13 & $11(84.6 \%)$ & $2(15.4 \%)$ & $0(0 \%)$ \\
\hline Educational status* & & & & \\
\hline Illiterate & 16 & $15(93.8 \%)$ & $1(6.3 \%)$ & $0(0 \%)$ \\
\hline Up to $\mathrm{V}$ & 32 & $28(87.5 \%)$ & $4(12.5 \%)$ & $0(0 \%)$ \\
\hline Up to SSC & 8 & $8(100 \%)$ & $0(0 \%)$ & $0(0 \%)$ \\
\hline Up to HSC & 14 & $10(17.1 \%)$ & $1(7.1 \%)$ & $3(21.4 \%)$ \\
\hline Graduate & 12 & $10(83.3 \%)$ & $2(16.7 \%)$ & $0(0 \%)$ \\
\hline Post graduate & 7 & $7(100 \%)$ & $0(0 \%)$ & $0(0 \%)$ \\
\hline Occupation & & & & \\
\hline Government & 10 & $9(90 \%)$ & $1(10 \%)$ & $0(0 \%)$ \\
\hline Non government & 3 & $2(66.7 \%)$ & $1(33.3 \%)$ & $0(0 \%)$ \\
\hline Business & 12 & $11(91.7 \%)$ & $1(8.3 \%)$ & $0(0 \%)$ \\
\hline Student & 13 & $11(84.6 \%)$ & $0(0 \%)$ & $2(15.4 \%)$ \\
\hline Housewife & 18 & $18(100 \%)$ & $0(0 \%)$ & $0(0 \%)$ \\
\hline Day laborer & 11 & $8(72.7 \%)$ & $3(27.3 \%)$ & $0(0 \%)$ \\
\hline Farmer & 5 & $4(80 \%)$ & $1(20 \%)$ & $0(0 \%)$ \\
\hline Driver & 5 & $4(80 \%)$ & $0(0 \%)$ & $1(20 \%)$ \\
\hline Unemployed & 4 & $4(100 \%)$ & $0(0 \%)$ & $0(0 \%)$ \\
\hline Security guard & 4 & $4(100 \%)$ & $0(0 \%)$ & $0(0 \%)$ \\
\hline Factory worker & 4 & $3(75 \%)$ & $1(25 \%)$ & $0(0 \%)$ \\
\hline Smoking habit & & & & \\
\hline No & 42 & $35(83.3 \%)$ & $5(11.9 \%)$ & $2(4.8 \%)$ \\
\hline Yes & 47 & $43(91.5 \%)$ & $3(6.45 \%)$ & $1(2.1 \%)$ \\
\hline Number of sticks & & & & \\
\hline NA & 41 & $35(85.4 \%)$ & $5(12.2 \%)$ & $1(2.4 \%)$ \\
\hline$<5 /$ day & 4 & $4(100 \%)$ & $0(0 \%)$ & $0(0 \%)$ \\
\hline $5-10 /$ day & 26 & $24(92.3 \%)$ & $1(3.8 \%)$ & $1(3.8 \%)$ \\
\hline 11-15/day & 11 & $9(81.8 \%)$ & $2(18.2 \%)$ & $0(0 \%)$ \\
\hline 15-20/day & 7 & $6(85.7 \%)$ & $0(0 \%)$ & $1(14.3 \%)$ \\
\hline Duration of smoking & & & & \\
\hline NA & 41 & $35(85.4 \%)$ & $5(12.2 \%)$ & $1(2.4 \%)$ \\
\hline$<5 \mathrm{yRs}$ & 8 & $8(100 \%)$ & $0(0 \%)$ & $0(0 \%)$ \\
\hline $6-10 \mathrm{yrs}$ & 21 & $19(90.5 \%)$ & $1(4.8 \%)$ & $1(4.8 \%)$ \\
\hline $11-15 \mathrm{yrs}$ & 13 & $11(84.6 \%)$ & $1(7.7 \%)$ & $1(7.7 \%)$ \\
\hline $16-20 \mathrm{yrs}$ & 5 & $4(80 \%)$ & $1(20 \%)$ & $0(0 \%)$ \\
\hline$>20$ yrs & 1 & $1(100 \%)$ & $0(0 \%)$ & $0(0 \%)$ \\
\hline Betel leaf & & & & \\
\hline No & 48 & $41(85.4 \%)$ & $5(10.4 \%)$ & $2(4.2 \%)$ \\
\hline Yes & 41 & $37(90.2 \%)$ & $3(7.3 \%)$ & $1(2.4 \%)$ \\
\hline Jarda & & & & \\
\hline No & 53 & $46(86.8 \%)$ & $5(9.4 \%)$ & $2(3.8 \%)$ \\
\hline Yes & 36 & $32(88.9 \%)$ & $3(8.3 \%)$ & $1(2.8 \%)$ \\
\hline
\end{tabular}

* Significant 
Table 2: Endoscopic finding and H. pylori status of the study population $(n=89)$

\begin{tabular}{|l|c|c|c|}
\hline $\begin{array}{c}\text { Endoscopic finding } \\
(\mathbf{n = 8 9})\end{array}$ & $\begin{array}{c}\text { H. pylori + status } \\
(\mathbf{n}=\mathbf{7 8})\end{array}$ & $\begin{array}{c}\text { H. pylori }- \text { status } \\
(\mathbf{n}=\mathbf{8})\end{array}$ & $\begin{array}{c}\text { Indeterminate } \\
(\mathbf{n}=\mathbf{3})\end{array}$ \\
\hline Duodenal Ulcer $(\mathrm{n}=54)$ & $47(91.5 \%)$ & $7(8.5 \%)$ & $0(0 \%)$ \\
\hline DU + DB $(\mathrm{n}=1)$ & $1(100 \%)$ & $0(0 \%)$ & $0(0 \%)$ \\
\hline Gastric Ulcer $(\mathrm{n}=5)$ & $5(100 \%)$ & $0(0 \%)$ & $0(0 \%)$ \\
\hline Antral Erosion $(\mathrm{n}=24)$ & $23(95.8 \%)$ & $0(0 \%)$ & $1(4.2 \%)$ \\
\hline GU + DU (n=4) & $2(50 \%)$ & $1(25 \%)$ & $1(25 \%)$ \\
\hline Prepyloric erosion $(\mathrm{n}=1)$ & $0(0 \%)$ & $0(0 \%)$ & $1(100 \%)$ \\
\hline
\end{tabular}

So the monoclonal SAT revealed $92.3 \%$ sensitivity and specificity of $100 \%$ before treatment. Indeterminate results were excluded from the monoclonal stool antigen assay before treatment. Among 52 follow-up patients (after treatment), $5(9.6 \%)$ patients were detected positive by histology, RUT and stool antigen test, and 35 (67.3\%) patients were negative by 3 tests (Table 4 ). Remaining 12 $(23.1 \%)$ indeterminate cases were excluded from further statistical analysis. So the monoclonal SAT revealed 100\% sensitivity and $100 \%$ specificity after treatment.

\section{Discussion}

$H$. pylori infection is one of the most common infections in human beings worldwide, strongly associated with peptic ulcer disease and gastric cancer. ${ }^{23,24}$ Detection of $H$. pylori infection has therefore become a key step in the management of patients referred to gastroenterologists. There are several methods available to detect $H$. pylori infection including invasive methods based on gastric biopsies and non-invasive methods like serology, urea breath tests, and stool antigen tests. ${ }^{25,26}$ Stool antigen tests have recently been welcomed with great expectations as they are convenient to the patients and can be easily performed even in small laboratories. ${ }^{27,28}$ However, the accuracy of stool antigen tests in different clinical situations and outside of controlled studies is a matter of concern. ${ }^{29-31}$

Table 3: Stool Antigen test and H. pylori status of the study population before treatment

\begin{tabular}{|l|c|c|c|}
\hline $\begin{array}{l}\text { H. pylori } \\
\text { status }\end{array}$ & $\begin{array}{c}\text { No of } \\
\text { respondents }\end{array}$ & Stool Ag +ve & Stool Ag -ve \\
\hline Positive & 78 & $72(92.3 \%)$ & $6(7.7 \%)$ \\
\hline Negative & 8 & $0(0 \%)$ & $8(100 \%)$ \\
\hline
\end{tabular}

$\chi^{2}=45.36, \mathrm{p}<0.001$

In the present study, $87.6 \%$ of patients with peptic ulcers were found to be $H$. pylori positive before treatment which corresponds to the findings $(86.2 \%)$ of a study conducted by Karahan et $a l .{ }^{32}$ in Turkey. This is in contrast to lower detection rate of $44.2 \% \mathrm{H}$. pylori positive cases by Asfeldt et $a l .^{16}$ in Norway and $55 \%$ by Trevisani et $a l .^{33}$ in Italy. The higher detection rate in this study is probably due to that the study was done in developing country where $80-90 \%$ of population has $H$. pylori.

Table 4: Stool Antigen test and H. pylori status of the study

\begin{tabular}{|l|c|c|c|}
\hline $\begin{array}{l}\text { H. pylori } \\
\text { status }\end{array}$ & $\begin{array}{c}\text { No of } \\
\text { respondents }\end{array}$ & Stool Ag +ve & Stool Ag -ve \\
\hline Positive & $5(9.6 \%)$ & $5(100 \%)$ & $0(0 \%)$ \\
\hline Negative & $35(67.3 \%)$ & $0(0 \%)$ & $35(100 \%)$ \\
\hline Indeterminate & $12(23.1 \%)$ & $0(0 \%)$ & $12(100 \%)$ \\
\hline
\end{tabular}

$\chi^{2}=52.00, \mathrm{p}<0.001$

population after 4 weeks treatment

The present study also demonstrated that $H$. pylori was found positive in $91.5 \%$ of duodenal ulcer and $95.8 \%$ antral erosion patients. Similarly Karahan et al. ${ }^{32}$ found $100 \%$ and $90.5 \% \mathrm{H}$. pylori status positive among duodenal ulcer and antral erosion cases. Dominguez-Bello et al. ${ }^{34}$ also found $96.7 \% \mathrm{H}$. pylori status positive among duodenal ulcer cases and $19 \%$ in erosive gastritis in Spain. This difference in erosive cases might be due to variation in age, economic status and ethnic background of the patients. The present study also demonstrated that monoclonal SAT was positive in $92.3 \% \mathrm{H}$. pylori positive status which is similar to the studies conducted in Turkey ${ }^{32}(92 \%)$, Norway ${ }^{16}(98.1 \%)$ and in Malaysia $^{35}$ (97.8\%). We found $7.7 \%$ showed false negative results and no false positive results. Asfeldt et al. ${ }^{16}$ identified $5.8 \%$ false negative and $1.8 \%$ false positive result. The reasons for false negative might be due to decreased bacterial density accompanied by low $H$. pylori stool antigen optical density leading to an erroneous diagnosis, and high genetic variability of bacterium leading to high variability of antigenic epitopes.

Sensitivity of monoclonal stool antigen for $H$. pylori in this study before treatment was $92.31 \%$ and specificity $100 \%$. Asfeldt et $a l .^{16}$ and Bhewa et $a l^{35}$ reported higher monoclonal SAT sensitivity and specificity. Gisbert et al. ${ }^{36}$ carried out a systematic review and meta-analysis on the accuracy of these tests for diagnosis and for treatment 
follow up and found pooled sensitivity and specificity were $94 \%$ and $97 \%$ respectively. High sensitivity and high specificity of monoclonal SAT due to use of monoclonal antibodies provides more concordant results between different kits. In case of the polyclonal $H$. pylori stool antigen test (rabbit origin), the antibodies in different kits come from different animals, giving rise to a different profile of antibodies. This leads inconsistency in results and overall a less reproducible test.

In this study, $9.6 \%$ were found to be $H$. pylori positive 4 weeks after treatment, $67.3 \%$ were found to be $H$. pylori negative, and remaining $23.1 \%$ had indeterminate result. Tasch et al. ${ }^{37}$ also found $13.6 \% \mathrm{H}$. pylori positive and $86.4 \%$ H. pylori negative according to predefined criteria. Asfeldt et al. ${ }^{16}$ similarly found $100 \%$ patients were negative by stool test and reference standard at follow up. In the present study, sensitivity and specificity of the monoclonal SAT was $100 \%$ and $100 \%$ respectively 4 wks after treatment. Similarly Asfeldt et al. ${ }^{16}$ and Weingat et al. ${ }^{38}$ found similar sensitivity and specificity after 6 weeks eradication therapy.

This study has a few limitations. First, the data was a crosssectional; therefore, we can only postulate an association but not casualty between $H$. pylori and peptic ulceration. Secondly, the data were obtained in a specialized hospital from the population of the capital city and may not be generalized to other population of the country, especially rural areas.

\section{Conclusion}

The monoclonal SAT is a highly sensitive and specific tool for diagnosis of $H$. pylori infection, and can assess the success of eradication after therapy. It also offers the advantage of specificity and reliability over the invasive test. It is an easy to use, rapid test and does not require any special technology. In the present study, $87.6 \%$ of patients were found to be $H$. pylori positive before treatment. The monoclonal SAT was positive in $92.3 \% \mathrm{H}$. pylori positive patients, and $100 \%$ negative among $H$. pylori negative status patients. The monoclonal SAT revealed 92.3\% sensitivity and specificity of $100 \%$ before treatment, and $100 \%$ sensitivity and $100 \%$ specificity after treatment. Based on this performance, monoclonal SAT can be used for screening $H$. pylori infection and assessing efficacy of treatment in the various healthcare settings of Bangladesh.

\section{References}

1. Marshall BJ. History of the discovery of Campylobacter pylori, In: Blaser $\mathrm{MJ}$, ed. Campylobacter pylori in gastritis and peptic ulcer disease, 1989.

2. Go MF. Review article: natural history and epidemiology of Helicobacter pylori infection. Aliment Pharmacol Ther 2002;16 (Suppl 1):3-15.

3. Schöttker B, Adamu MA, Weck MN, Brenner H.
Helicobacter pylori infection is strongly associated with gastric and duodenal ulcers in a large prospective study. Clin Gastroenterol Hepatol 2012;10(5):487-93

4. Marshall BJ and Warren JR. Unidentified curved bacilli in the stomach patients with gastritis and petic ulceration. Lancet 1984;1:1311-5.

5. Matsuhisa T, Aftab H. Observation of gastric mucosa in Bangladesh, the country with the lowest incidence of gastric cancer, and Japan, the country with the highest incidence. Helicobacter 2012;17:396-401.

6. Sarker SA, Mahmud H, Davidsson L, Alam NH, Ahmed T, Alam N, et al. Causal relationship of Helicobacter pylori with iron-deficiency anemia or failure of iron supplementation in children. Gastroenterology 2008;135:1534-42.

7. Qureshi H, Ahmed W and Syed S. Helicobacter pylori clearance and its eradication in duodenal ulcer patients. JPakMed Assoc 1995;42:2-5.

8. Feldman RA. Prevention of Helicobacter pylori infection In: Calam J (ed). Helicobacter pylori. London: Balliere Tindall, 1995.

9. Russel RG, Wasserman SS, O’Donnoghue JM. Serologic response to Helicobacter pylori among children and teenagers in northern Chile. Am J Trop Med and Hyg 1993;49:189-91.

10. Lambert JR. Helicobacter pylori. Scand J Gastoenterol 1995;208:33-46.

11. Cover TL, Blaser MJ. The pathobiology of Campylobacter infections in human. Ann Rev Med 1989;40:269-85.

12. Andrews J, Espersen F, Wyatt JI, Dixon MF. () Comparison of three stool antigen tests for Helicobacter pylori detection. J Clin Pathol 2003;56:769-71.

13. Adachi K, Kawainura A, Ono M, Masuzaki K, Takashima T, Yuki M, et al. Comparative evaluation of urine-based and other minimally invasive methods for the diagnosis of Helicobacter pylori infection, $J$ Gastroenlcro 2002;37:703-8.

14. Arenls NL, Zweet AA, Thijs JC, de Jong A, Pool MO, Kleibeuker JH. The accuracy of the Helicobacter pylori stool antigen test in diagnosing $H$. pylori in treated and untreated patients. Eur $J$ Gastroenterol Hepatol 200113:383-6.

15. Leodolter A, Peitz U, Kbert MP, Agha-Amiri K, Malfertlicincr P. Comparison of two enzyme immunoassays for the assessment of Helicobacter pylori status in stool specimens after eradication therapy. Am J Gastroenterol 2002;97:1682-6.

16. Asfeldt AM, Lochen ML, Straume B, Steigen SE, Florholmen J, Goll R, et al. Accuracy of a Monoclonal Antibody-based Stool Antigen test in the Diagnosis of 
Helicobacter pylori Infection. Scand J Gastroenterol 2004;39:1073-7.

17. Vakil N, Affi A, Robinson J, Sumdaram M, Phadnis S. Prospective blinded trial of a fecal antigen test for the detection of Helicobacter pylori infection. Am J Gastroenterol 2000;95:1699-701.

18. Masoero G, Lombardo L, Monica P, Vicari S, Crocilla C. Duglio A, et al. Discrepancy between Helicobacter pylori stool antigen assay and urea breath test in the detection of Helicobacter pylori infection. Dig Liver Dis 2000;32:285-90.

19. Quesada M, Calvet X, Dosal A, Calvet V, Sanfeliu I, Ribera L, et al. Evaluation of four different fecal tests for determination of cure after Helicobacter pylori treatment. JClin Gastroenterol 2006;40:790-4.

20. Kolho KL, Klemola T, Koivusalo A, Rautelin H. Stool antigen tests for the detection Helicobacter pylori in children. Diagn Microbiol Infect Dis 2006;55:269-73.

21. Hooton C, Keohane J, Clair J, Azam M, O(Mahony S, Crosbie $\mathrm{O}$, et al. Comparison of three stool antigen assays with the $13 \mathrm{C}$-urea breath test for the primary diagnosis of Helicobacter pylori infection and monitoring treatment outcome. Eur J Gastroenterol Hepatol 2006;18:595-9.

22. Frenck RW, Fathy HM, Sherif M, Mohran Z, El Mohammedy H, Francis W, et al. Sensitivity and specificity of various tests for the diagnosis of Helicobacter pylori in Egyptian children. Pediatrics 2006;118:e1195-2002.

23. International Agency for Research on Cancer. Schistosomes, liver flukes and Helicobacter pylori. IARC Working Group on the Evaluation of Carcinogenic Risks to Humans. Lyon, 7-14 June 1994. IARC Monogr Eval Carcinog Risks Hum 1994; 61:1241.

24. Fox JG, Wang TC. Helicobacter pylori--not a good bug after all! NEngl J Med 2001; 345: 829-32.

25. Nakamura R. Laboratory tests for the evaluation of Helicobacter pylori infections. J Clin Lab Anal 2001;15:301-7.

26. Vakil N. Review article: the cost of diagnosing Helicobacter pylori infection. Aliment Pharmacol Ther 2001;15 (Suppl 1):10-15.

27. Malfertheiner P, Megraud F, O'Morain C, Hungin AP, Jones R, Axon A, et al. Current concepts in the management of Helicobacter pylori infection--the Maastricht 2-2000 Consensus Report. Aliment Pharmacol Ther 2002;16:167-80.
28. Vaira D, Ricci C, Menegatti M, Gatta L, Berardi S, Tampieri A, et al. Stool test for Helicobacter pylori. Am J Gastroenterol2001;96:1935-8.

29. Parente F, Maconi G, Porro GB, Caselli M. Stool test with polyclonal antibodies for monitoring Helicobacter pylori eradication in adults: a critical reappraisal. Scand J Gastroenterol 2002; 37: 747-9.

30. Gisbert JP, Pajares JM. Stool antigen test for the diagnosis of Helicobacter pylori infection: a systematic review. Helicobacter 2004;9:347-68.

31. Hunt R, Fallone C, Veldhuyzan van Zanten S, Sherman P, Smaill F, Flook N, Thomson A. Canadian Helicobacter Study Group Consensus Conference: Update on the management of Helicobacter pylori--an evidence-based evaluation of six topics relevant to clinical outcomes in patients evaluated for $\mathrm{H}$ pylori infection. Can J Gastroenterol 2004; 18:547-54.

32. Karahan Z C, Bostanoglu E, Bostanoglu A, Savas B, Erden E, Kiyan M. Evaluation of the presence of Helicobacter species in the biliary system of Turkish patients with cholelithiasis. Turkish J Gastroenterol 2010;21:421-7.

33. Trevisani L, Sartori S, Galvani F, Rossi MR, Ruina M, Caselli M. Detection of Helicobacter pylori in faeces with a new enzyme immunoassay method: preliminary results. Scand J Gastroenterol 1998;33:893-5.

34. Dominguez-Bello MG, Blaser MJ. The Human Microbiota as a Marker for Migrations of Individuals and Populations. Annu Rev Anthropol 2000;40:451-74.

35. Bhewa Y, Hilmi I, Cheah PL, Navaratnam P, Goh KL. Evaluation of the monoclonal stool antigen test for Helicobacter pylori in an Asian population with dyspepsia. J Dig Dis 2007;8:207-10.

36. Gisbert JP, Calvet X, Bujanda L, Marcos S, Gisbert JL, Pajares JM. Rescue' therapy with rifabutin after multiple Helicobacter pylori treatment failures. Helicobacter 2003;8:90-4.

37. Tasch C, Konstantopoulos N, Russmann H, et al. Evaluation of the Helicobacter pylori stool antigen test for detection of Helicobacter pylori infection in children. Am J Gastroenterol 2001;96:677-83.

38. Weingart V, Russmann H, Koletzko S, Weingart J, Hochter W, Sackmann M. Sensitivity of a novel stool antigen test for detection of Helicobacter pylori in adult outpatients before and after eradication therapy. $J$ Clin Microbiol 2004;42:1319-21. 